\title{
Growth and Form: What is the Aim of Biomineralization?
}

\author{
Edmund Bäuerlein
}

\begin{abstract}
12-Amino-acid peptides with binding-selected sequences and random functional groups synthesize the same inorganic material. Bacteria use structured polymers as filaments of cytoskeletal protein and of polysaccharides in templating biominerals. Nucleation appears to be involved not only in crystal formation, but also in the formation of porous or amorphous inorganic material. A seed of one iron ion for an iron-oxide cluster could be obtained in the low-iron-state of an archeal ferritin crystal. Porous inorganic materials were described to grow out in huge channeled complexes of organic compounds or crystallized seawater. The evolutionary progress of biomineralization runs apparently in the development of complex, inorganic-organic hybrid materials, composites, which are often structured hierarchically. The mechanical properties of a mineral undergo a change by presence and partition of the organic material, the most prominent example being the human skeleton. In order to describe such a complex system, a mathematical procedure - the finite element analysis - was introduced with great success. This analysis is governed amazingly by only one physical quantity, force, together with the modulus of elasticity. The overwhelming extent of research into the mechanical properties of skeletons has resulted in the conclusion that the aim of biomineralization appears to be stability.
\end{abstract}

Key words: peptides, induced structures, low homologies, nucleation, filaments, pores, polysaccharides, unified theory, composites, finite element analysis, stability.

\section{1}

\section{Introduction}

A shortened title of an extraordinary book written by D'Arcy Wentworth Thompson, On Growth and Form [1], published in 1917, opens this first volume of the 
Handbook of Biomineralization. It refers to an "Abridged Edition" of the illustrious biologist John Tyler Bonner (Princetown) by the same publishing house in 1961 [2]. Bonner's fundamental experimental research on the height and life cycle of slime molds favored him with the competence to shorten and comment on this important work [3].

Whereas D'Arcy Thompson initiated the development of a general relationship between the growth and form of cells and tissues, this chapter focuses on the interaction between inorganic materials and organic (including prebiotic) compounds up to organisms, which are able to synthesize and shape biominerals.

\section{2}

\section{Notions of D'Arcy Thompson on Deposition of Inorganic Material in Cells}

The outstanding merit of Thompson's book is the introduction of mathematical and physical methods into the biology of growth and form in 1917. This broad field of research is covered today by biophysics, bioinformatics and quantitative system biology to such an extent that could not have been expected previously. Although the center of his interest was the development and shaping of cells, D'Arcy Thompson did not ignore biomineralization. Within his book of nine chapters, he attended one of those to "On Spicules and Spicular Skeletons". This is based on the view that "... deposition of inorganic material in living cells is a frequent phenomenon”. Later, J.T. Bonner summarized precisely the fixed opinion of the author [2a]: "In this chapter and the following ones D'Arcy Thompson is struggling against the notion that all form can simply be explained by heredity, and that therefore changes in form inevitably map out phylogenetic relations. Instead he repeatedly suggests that physical forces (such as those which produce the variations of shapes of snowflakes) are of prime importance and relationships of shape may not justify any family tree or sequence in time, but simply show mathematical kinship."

Indeed, the excellent structural research of biominerals within the past 20 to 30 years appears to be strongly affected by these physical and mathematical approaches.

Nevertheless, in 2000 J. Kirschvink risked outlining "A Grand Unified Theory on Biomineralization" [4]. This draft was based mainly on morphological changes, and began with the earliest known biosynthesis of a mineral, speciesspecific magnetite nanoparticles in magnetotactic bacteria. This idea fascinated many of us that magnetite biomineralization might be an "evolutionary procedure" for most biominerals during evolution.

One year later, in 2001, the new combined method of molecular biology and genome sequencing invaded biomineralization. This era began with the almostcomplete genome sequences of two magnetotactic bacteria, which were generously offered to the scientific public in January 2001 by the Joint Genome Institutes, DOE, US Government (thanks to Prof. Ken Nealson). By using sequence comparison, no genes could be found with high similarities to those involved in magnetite biomineralization (see Chapter 9 in this volume). 


\section{3}

\section{Close to the Beginning of Biomineralization}

\subsection{1}

\section{Prebiotic Synthesis of Peptides}

Today, carbon compounds such as amino acids, sugars and heterocycles, which are described as organic compounds from the time after the origin of life, may be synthesized in laboratories under a variety of prebiotic reaction conditions [5].

The prebiotic origin of peptides is of special interest to the first phenomena of biomineralization. Basalt, a volcanic rock composed of various silicates, was used as catalyst in prebiotic mode reaction, with a mixture of all amino acids reacting in the presence of basalt at $180{ }^{\circ} \mathrm{C}$ to peptides, via the loss of water [6]. On the basis of these preliminary experiments it could not have been foreseen that the tight binding of the products - the peptides - might represent an important step in the interaction of prebiotic "organic" compounds and minerals in the development of the first cells [7].

\subsection{2}

\section{Selected Binding of Phage(Virus)-Displayed Peptides to Inorganic Materials}

It was the unique intuition of A. Belcher which made her seek for specific interaction, the goal being to identify families of amino acid sequences that could bind differentially to specific faces and polymorphs of the substrate of interest [8a].

At this time, "Combinatorial Phage Display Peptide Libraries" first became commercially available [9]. These peptide libraries were the result of a gigantic random peptide synthesis initiative, based on molecular biology. For example, about $3 \times 10^{9}$ distinct random sequences are present as combinations of 12 random amino acids. Each of these 12-amino-acid peptides is expressed as a fusion with a small surface displayed protein (called III) of the bacteriophage M13 (a virus) which infects only bacteria. In addition, each virus molecule has placed five copies of its protein III onto the surface, and provides there consequently five identical peptides. Each 12-amino-acid peptide sequence is amplified to yield about 55 copies per volume, as used by Belcher in the selection steps with electronic material. These were gallium arsenide, indium phosphide and zinc sulfide, as well as crystals of biominerals such as calcite and aragonite - two common polymorphs of calcium carbonate found in many organisms.

\section{3 .3}

\section{Synthesis of Inorganic Material by Selected Peptides}

M.O. Stone did not use this method only to select for peptides that bind specifically to inorganic materials. Rather, his brilliant idea was to determine whether such phage-displayed peptides could be capable of generating those inorganic structures to which they had bound. The success of this extended analysis was extraordinary in a variety of directions. In the first experiment, Stone's group ex- 


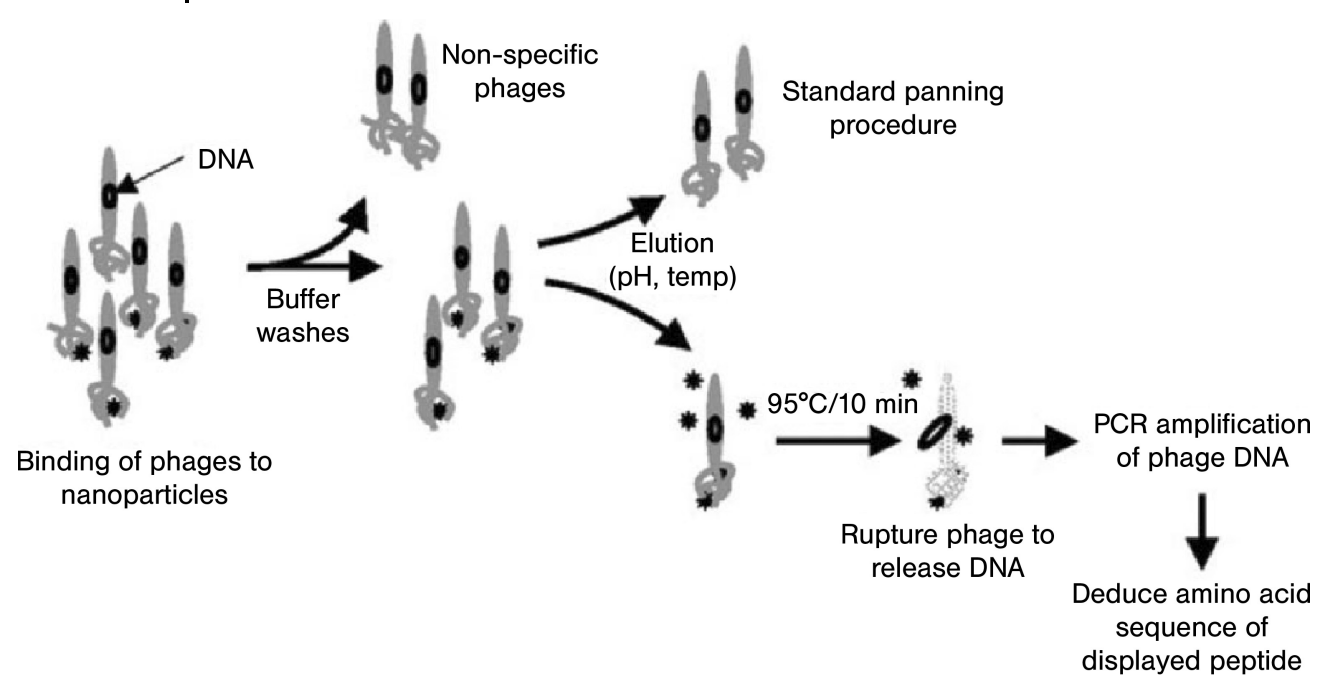

Fig. 1.1 Schematic illustration of regular and polymerase chain reaction (PCR)-driven phage panning for peptides that bind to inorganic nanoparticles. (According to [10c]; courtesy of M.O. Stone.)

amined those peptides which were selected by their binding capacity on silica particles [10a] for the formation of these particles by orthosilicic acid. This peptidemediated material synthesis resulted in the greatest quantities of silica when amino acids containing hydroxyl-, imidazole- and high cationic groups were present in the 12-amino-acid peptides. This population of phage-displayed peptides was obtained by a standard panning procedure (Fig. 1.1), which included several amplification steps by infections of Escherichia coli host cells with the selected phage-displayed peptides [10a]. They appeared to act enzyme-like by definite residues in binding as well as in material production [11]. Although such similarity was found, it was questioned at the same time by the results of peptide-mediated synthesis and the patterning of silver nanoparticles [10b]. Three silver-binding peptides indicated a preferential enrichment of proline and hydroxyl-residues containing amino acids, but not of any sulfur-containing amino acids such as cysteine or methionine. Two of these three phage-displayed peptides precipitated silver nanocrystals.

This fascinating study reached its climax, when a new method - polymerase chain reaction (PCR)-driven panning - was used instead of a regular phage panning (Fig. 1.1). The results with silver will not be discussed in detail here, in favor of more extended experiments with cobalt nanoparticles, but they are listed in Table 1.1.

The question of whether some of these peptides remained bound following a low-pH incubation step was answered when three sets of cobalt-binding phagedisplayed peptides were obtained. Both methods - "regular panning" and PCRdriven - are likely to be characterized very shortly. "Regular panning" is carried out by incubating the library of phage-displayed peptides with a target (in this 
Table 1.1 Silver-binding peptides. ${ }^{\text {a }}$

\begin{tabular}{lll} 
PCR method & Regular panning \\
\hline AG-P1 & $\begin{array}{l}\text { KFLQFVCLGVGP AG3 } \\
\text { AYSSGAPPMPPF }\end{array}$ & AG3 AYSSGAPPMPPF \\
AG-P2 & AVLMQKYHQLGP AG4 & \\
& NPSSLFRYLSD & AG4 NPSSLFRYLPD \\
AG-P6 & QQNVPASGTCSI & AG5 SLATQPPRTPPV \\
AG-P10 NAMPGMVAWLCR & \\
AG-P11 & HNTSPSPIILTP & \\
AG-P12 & ASQTLLLPVPL & \\
AG-P14 & YNKDRYEMQAPP & \\
AG-P18 & TLLLLAFVHTRH & \\
AG-P27 & PWATAVSGCFAP & \\
AG-P28 & SPLLYATTSNQS \\
AG-P35 & WSWRSPTPHWT & \\
\end{tabular}

a According to Ref. [10c]; courtesy of M.O. Stone.

case cobalt nanoparticles), washing away unbound/non-specific phages, and eluting the bound phages using a low-pH incubation step (see Fig. 1.1). The eluted phages are amplified and subjected to additional "panning" rounds in order to obtain highly enriched binding sequences. A high number of phage-displayed peptides remained strongly bound to the cobalt nanoparticles, even after an extended acid elution step. These were identified using a PCR-driven method, which is much more rapidly performed than "regular panning". In both methods, the first steps before or after acid solution were essentially the same, after which the corresponding cobalt nanoparticles were incubated in lysis buffer for $10 \mathrm{~min}$ at $95{ }^{\circ} \mathrm{C}$ to disrupt the phage coat; this resulted in phage DNA release. The PCR reaction, when mixed with a specific set of DNA primers [12], was added directly to the cobalt nanoparticles.

Following the PCR reaction, the samples were separated on an agarose gel. The DNA fragments obtained were cloned into a plasmid, and DNA sequencing was performed to derive the amino acid sequences of the phage-displayed peptides.

The amino acid sequences of these cobalt-binding peptides are listed in Table 1.2 (no discussion will be made at this point as to why Set II does not represent all sequences of Set I plus those of Set III). Moreover, Set II included seven sequences which did not belong to either Set I or Set III, which probably indicated that insufficient clones had been sequenced, this being an extremely laborintensive project and not the aim of this publication. 
Table 1.2 Cobalt-binding peptides. ${ }^{a}$

\begin{tabular}{|c|c|c|}
\hline $\begin{array}{l}\text { Eluted cobalt nanoparticles } \\
\text { (Set I) }\end{array}$ & $\begin{array}{l}\text { Uneluted cobalt nanoparticles } \\
\text { (Set II) }\end{array}$ & Regular panning (Set III) \\
\hline Co1-P1 HSVRWLLPGAHP & Co2-P4 HSVRWLLPGAHP & Co3-P12 GTSTFNSVPVRD \\
\hline Co1-P2 HETNPPATIMPH & Co2-P3 SAPNLNALSAAS & Co3-P13 SAPNLNALSAAS \\
\hline Co1-P3 WASAAWLVHSTI & Co2-P5 SVSVGMKPSPRP & Co3-P1 SVSVGMKPSPRI \\
\hline Co1-P4 SPLQVLPYQGYV & Co2-P8 SPLQVLPYQGYV & Co3-P16 VPTNVQLQTPRS \\
\hline Co1-P5 ESIPALAGLSDK & Co2-P1 SLTQTVTPWAFY & \\
\hline Co1-P6 GVLNAAQTWALS & Co2-P7 TNLDDSYPLHHL & \\
\hline Co1-P8 TPNSDALLTPAL & Co2-P6 TPNSDALLTPAL & \\
\hline Co1-P10 HYPTLPLGSSTY & Co2-P12 HYPTLPLGSSTY & \\
\hline Co1-P13 HAMRPQVHPNYA & Co2-P9 TQQTDSRPPVLL & \\
\hline Co1-P15 QYKHНPQKAAHI & Co2-P14 QYKHHPQKAAHI & \\
\hline Co1-P16 YGNQTPYWYPHR & Co2-P11 TFPSHLATSTQP & \\
\hline Co1-P17 HPPTDGMVPSPP & Co2-P13 QNFLQVIRNAPR & \\
\hline Co1-P18 TWQPFGMRPSDP & Co2-P2 KLHSSPHTPLVQ & \\
\hline Co1-P21 TGDVSNNPNVTL & Co2-P17 QLLPLTPSLLQA & \\
\hline
\end{tabular}

a According to Ref. [10c]; courtesy of M.O. Stone.

\section{3 .4}

\section{Selected Sequences with Various Functional Groups}

The standard procedure of binding, washing and acid-eluting followed by amplification in E. coli host cells - which is referred to as regular panning (Fig. 1.1) was used initially in the isolation of four selected phage-displayed peptides with some functional groups on their 12-amino-acid sequences. Among these four peptides, neither histidine $(\mathrm{H})$ nor glutamic acid (E) (Table 1.1) - both of which are known to bind specifically to cobalt [13] - were found.

Moreover, the PCR method (Fig. 1.1) yielded at least 25 phage-displayed peptides (Table 1.2) which had resisted high-stringency washing conditions. Between one and three histidines $(\mathrm{H})$ were present in nine of these 25 peptide sequences, whereas glutamic acid was identified in only one peptide sequence.

Three peptides of Set I (Co1-P1, Co1-P10 and Co1-P15) and one peptide of Set II were synthesized chemically [14] (Table 1.3) in order to exclude possible interactions of, or precipitation on, the phage (virus) surface during mineral synthesis. This study was not conducted to obtain knowledge of these peptides as templates for cobalt nanoparticles, but rather for the synthesis of cobalt-platinum nanoparticles. These nanoparticles are of major interest in materials chemistry because of their enhanced magnetic anisotropy and other positive properties [15]. Again, the lack of similarities among the four 12-amino-acid peptide sequences was obvious (Table 1.3), and all four resulted in the precipitation of the metal alloy Co-Pt, albeit with various crystal sizes [10c]. 
Table 1.3 Peptides synthesized chemically for the experiments.

\begin{tabular}{llll}
\hline & Amino acid sequence & Isoelectric pH (pl) & Panning method \\
\hline & & & \\
Silver-binding peptides & & & \\
AG-P3 & IRPAIHIIPISH & 9.7 & PCR \\
AG-P4 & NVIRASPPDTSY & 5.8 & PCR \\
AG-P5 & LAMPNTQADAPF & 3.8 & PCR \\
AG-P28 & SPLLYTTSNQS & 5.2 & PCR \\
AG-P35 & WSWRSPTPHVV & 9.7 & PCR \\
AG-4 & NPSSLFRYPSD & 6.1 & Regular \\
Cobalt-binding peptides & & & \\
Co1-P1 & HSVRWLLPGAHP & 9.7 & PCR \\
Co2-P2 & KLHSSPHTLPVQ & 8.6 & PCR \\
Co1-P10 & HYPTLPLGSSTT & 6.7 & PCR \\
Co1-P15 & QYKHHPQKAAHI & 9.7 & \\
\end{tabular}

a According to Ref. [10c]; courtesy of M.O. Stone.

\section{3 .5}

\section{Summary and Conclusion}

12-Amino-acid peptides bind very tightly to inorganic materials and produce this inorganic material, not by the action of any specific functional group but rather by a variety of selected sequences with various other functional groups. Whether each of these sequences or various induced secondary structures may be responsible for both interactions, binding to and producing of this corresponding inorganic material, remains an open question.

Some indications in favor of induced secondary structures were obtained from studies with poly-L-lysine (PLL), the molecular weight of which affected the morphology of silica precipitated in presence of silicic acid. A higher molecularweight PLL produced hexagonal silica platelets, whereas spherical silica particles were obtained using low-molecular-weight PLL. The polypeptide secondary structure transitions were determined from circular dichroism spectra [16].

\section{4}

Nucleation of Inorganic Crystals and Inorganic Amorphous/Porous Forms on Peptides

\subsection{1}

Porous Silica Spheres Synthesized by 12-Amino Acid Peptides Targets

12-Amino-acid peptides, when bound to silica nanoparticles, provide the simplest system for synthesizing the starting product, porous silica spheres (see Section 
1.3.3) [10a]. Formation of the alloy cobalt-platinum and of silver by using the same method created nano- and microcrystals. Thus, the question arises of whether porous or amorphous materials begin their formation and their shaping also by nucleation. Again, both mechanisms (see Section 1.3.4) impose the question of whether enzyme-like specific functional group(s) or selected sequences (either hydrophobic or hydrophilic) might be responsible for the origin of crystals or porous/amorphous forms, respectively. Initially, this question does not make sense, because in methodical terms it appears that no access exists for studying early clusters in terms of their preorder or disorder as a prerequisite for crystals or porous/amorphous particles.

\section{4 .2}

\section{An Amorphous $\mathrm{CaCO}_{3}$ Core and a Crystalline $\mathrm{CaCO}_{3}$ Envelope, Separated by an Organic Layer, Coexist on an Ascidian Skeleton}

An important report on ascidian skeletons by Aizenberg [17] suggested the possibility that the formation of skeletal crystalline calcium carbonate may begin with nucleation of an amorphous crystalline core (ACC). A detailed study revealed that each mineral phase contained characteristic proteins. Typically, on the one hand glycoproteins were extracted from the ACC, which was rich in glutamic acid and hydroxyamino acids, and on the other hand from the crystalline phase, which was rich in aspartic acid. Based on the results of in-vitro experiments, the ACC was stabilized by its acidic glycoprotein, which in addition inhibited the crystallization of calcite; otherwise, the aspartate-rich glycoprotein induced the formation of calcite crystals. The two calcium carbonate phases were separated in well-defined domains by an organic sheet. This highly organized system points to a very interesting inorganic/organic hybrid - namely, a composite with specific materials properties - rather than to an initial calcite crystallization by an amorphous phase.

\section{4 .3}

\section{The Proteomic Analysis of the Chicken Calcified Eggshell Layer}

Very recently, Mann reported the details of a proteomic analysis of an acid-soluble matrix of chicken calcified eggshell layer [18]. Here, knowledge of $90 \%$ of the chicken genome sequence was combined with Edman degradation sequencing of chromatographic separation, coupled to modern liquid chromatography (LC)mass spectrometry (MS)/MS method following protein cleavage.

Among 520 proteins, a group of 32 highly abundant proteins was described which contained ten previously characterized molecules. As yet, only a few of the mostly uncharacterized proteins have been characterized as acidic (for a discussion of this subject, see Volume 1, Chapters 16 and 18; see also Table 18.1). 
1.4.4

Synthesis of Nanocrystalline Hydroxyapatite with a Crystalline Core and a Disordered Surface Region

In synthesizing nanocrystalline hydroxyapatite, Epple succeeded in presenting a reverse order of nucleation [19] compared to the development of a complex composite ACC/calcite tissue in the ascidian skeleton study (see Section 1.4.2) [17]. Using transmission electron microscopy (TEM) and solid-state nuclear magnetic resonance (NMR), the nanocrystals were shown to consist of a crystalline core and a disordered surface region. The crystalline core was seen to be hydroxyapatite (HAp), and the surface region to be dominated by hydrogen phosphate anions, with no hydroxyapatite-like structural motif and structural water.

\section{4 .5}

\section{One Iron Atom in Archaeal Ferritin Crystals as Seed for an Iron-Oxide Cluster}

The Dps-like ferritin protein DpsA from the halophile Halobacterium salinarum is member of a second subfamily of ferritin. This differs from the ferritins by having 24 identical subunits, each of which shows outer and inner diameters of 12 and $8 \mathrm{~nm}$, respectively. By comparison, members of the Dps subfamily assemble only to protein shells of 12 identical subunits, with outer and inner diameters of 9 and $4.5 \mathrm{~nm}$, respectively. These ferritins therefore store only up to 110 iron atoms, compared to about 500 iron atoms in the case of eukaryotic and eubacterial ferritins.

One major advantage of the structural analysis of the DpsA protein was that three high-resolution structures could be determined at successively increasing iron contents [20]. For the low-iron state of DpsA with $1.6 \AA$ resolution, a single iron atom provides a structural seed for iron-oxide cluster formation at the nucleation center, NI. The $\mathrm{Fe}^{3+}$ of this subsite is coordinated prismatically to three symmetry-related glutamic acid residues and three symmetry-related water molecules. At this subsite, 13 water molecules form an unusual three-layered crown around the central $\mathrm{Fe}^{3+}$ ion. The next structure to be detected is an [4Fe-3O] cluster in the NII nucleation center; this is the first structural characterization of a nucleation event by one ion (atom) in which succeeded Vesterhelt.

\subsection{6}

\section{Directional Freezing of Aqueous Ceramic Suspensions to Shape Complex Composites}

Those of us not familiar with the physics of water will be excited for several reasons by the approach of Deville. Diatoms, coccolithophores and other impurities are concentrated within channels between the ice crystals of sea-water, because pure hexagonal ice platelets with randomly oriented horizontal crystallographic axis are formed [21]. Moreover, it is a fundamental finding that a critical particle 
size exists [22], above which the suspended particles will be trapped by the moving water-ice front. The application of both these experiences to produce complex composites is aided considerably by the fact that the hexagonal ice crystals exhibit strong anisotropic growth kinetics. The ice thus formed will have a lamellar microstructure, with the lamellar thickness depending mainly on the speed of the freezing front. The authors succeeded in building homogeneous, layered, porous scaffolds by freezing concentrated suspensions of ceramic particles above the critical particle size [23]. (For details, see Volume 2, Chapters 5 and 10.)

\subsection{7}

\section{Ways to Porous Structures}

A first analogy to these porous scaffolds presents itself in the formation of the porous silica-based cell walls of diatoms. A supramolecular assembly, termed the silaffin matrix, is formed spontaneously when the main organic compounds of these cell walls - long-chain polyamines (LCPA) and silaffins - are added together. LCPA are N-methylated derivatives of the oligo-propyleneimine chains, whereas silaffins (e.g., natSil2) are highly phosphorylated polypeptides. These matrices present two principles - a negative principle due to silaffins, and a positive principle due to LCPA - and are protonated at the acidic $\mathrm{pH}$ inside diatoms, in the silica deposition vesicles (SDV) [24]. (For details, see Volume 1, Chapter 3 and Volume 2, Chapter 2).

The huge, developing matrix remains invisible in water and may be isolated by centrifugation. It also exhibits silica precipitation activity by the addition of monomeric silicic acid. This matrix may be considered analogous to the ice matrix, and is assumed to be a network where, in the free space, the channels are filled by polymerizing silicic acid. Removal of these organic compounds may lead to an opening of the labyrinth of pores.

However, the discovery of three new silaffins in the model organism Thalassiosira pseudonana revealed that each silaffin, when mixed with LCPA, exhibits strikingly different effects on silica morphogenesis in vitro, either as:

- the formation of spherical silica particles, or

- porous sheets of silica, or

- the deposition of plates made from densely packed but extremely small silica particles, together with spherical silica particles.

This packing of silica particles traces the formation of porous silica back to the freezing technique (see Section 1.4.6; see also Volume 2, Chapter 10). The most important observation is that a critical particle size exists above which segregation - that is, the formation of multilayered porous ceramic structures - occurs. With increasing particle size, the space between the particles expands, leading most likely to a second type of pore which constitutes its own a labyrinth; this is an "open pore". When the channels are subsequently filled with another phase, the now dense complex composite may still possess pores of the second type. 
Very recently, a quantitative evaluation of porous materials in bones and bonesubstitute materials was introduced by Epple, who used microcomputed tomography followed by an algorithmic procedure to perform the analysis. More precise, quantitative data were obtained on the extent and type of porosity, and on their inner surface. The presence of an interconnecting pore system (of an "open pore") was shown convincingly for bone and all of the bone-substitute materials examined [25].

\section{5}

\section{Bacterial Filaments in the Advent of Biomineralization: Cytoskeleton-Like Proteins and Exopolysaccharides}

\subsection{1}

Proteins Responsible for the Alignment of Magnetosomes in Magnetotactic Bacteria

Bacteria are regarded as the simplest of all known unicellular organisms capable of synthesizing biominerals [26]. However, this superlative position has been questioned with the recent detection of a bacterial cytoskeleton containing tubulin and actin homologues [27a,b]; this was similar to eukaryotic actin and tubulin in terms of its three-dimensional (3-D) structure and biochemical properties.

\subsubsection{Actin-Like Filaments in Magnetotactic Bacteria}

Magnetotactic bacteria have roused special interest because they are able to utilize the Earth's magnetic field to achieve optimal life conditions. Single nanocrystals of magnetite $\left(\mathrm{Fe}_{3} \mathrm{O}_{4}\right)$, a magnetic iron oxide, when enveloped by a phospholipid membrane, are referred to as magnetosomes. These are aligned in the cytoplasm to form a chain which behaves like a compass needle. The construction of such a stable magnet of about 30 to 60 magnetosomes is the center of this biomineralization, most details of which were elucidated by Schüler when introducing modern molecular-genetic and protein chemical methods into biomineralization research (see Volume 1, Chapter 9).

A large genomic island, which encodes most of the specific, magnetosomeassociated proteins, was identified and designated as a "magnetosome island" [28], due mainly to its striking similarities to the "pathogenicity islands" identified in other bacteria [29].

The product of the mamJ gene is MamJ, an acidic protein which appears to interact with the magnetosome surface, as well as with an actin-like filament structure that directs the assembly and localization of the magnetosomes (Fig. 1.2). This cytoskeletal structure is very similar to that of the actin-like MreB proteins of other bacteria [27a,b], and is assumed to be formed by the mamK gene product [30]. Its deletion resulted in an absence of the magnetic filament(s) [31].

A major breakthrough in the analysis of detailed structure within intact shockfrozen cells was reported by Plitzko, who used cryoelectron tomography (as developed by its pioneer, Baumeister) [32] to display the cytoskeletal structures of wild- 


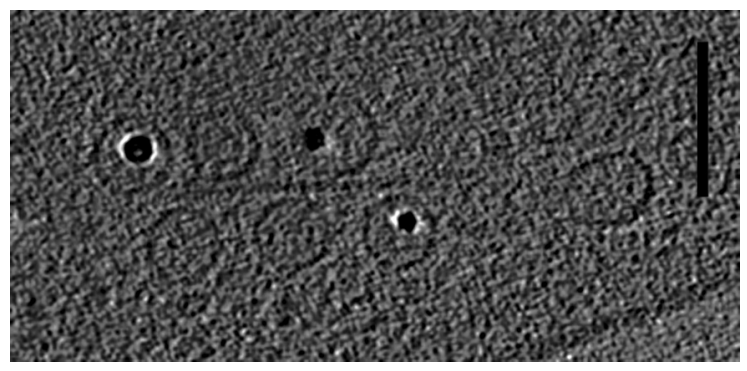

Fig. 1.2 A section of Magnetospirillum gryphiswaldense showing the cytoskeletal magnetosome filament. Magnetosome vesicles, which are empty or contain growing magnetite crystals, are attached to the filament. (Micrographs and visualization by J.M. Plitzko; see Volume 1, Chapter 9.)

type and mutant bacteria that were just a few nanometers in size (see Volume 1, Chapter 9; see also the front/back book cover, top left).

\subsubsection{Actin Filaments in Morphogenesis of Diatoms, Eukaryotic Unicellular Organisms}

Until today, a deep discrepancy has existed between those involved in research utilizing morphogenesis and those using molecular biology methods. Nevertheless, several studies of the morphogenesis of diatoms have shown that flagellinlike filaments appear to be involved in the formation of diatom shells (frustules). Thus, Kröger and Poulson (see Volume 1, Chapter 3), as leading proponents of molecular biology studies, point to the important review of Pickett-Heaps and colleagues on "Cell biology of diatom valve formation" [33], in which the following is described (see p. 109):
"In some scale-forming organisms, too, there is evidence that actin filaments are involved in morphogenesis. Microfilaments associated with the silica deposition vesicles (SDV) of scale forming vesicles in synura appear in a transient horse-shoe pattern of parallel, cross-linked fibres, attached directly to the membrane. They contain actin and may function in shaping the $S D V$, since they disappear once the shape of the scale has been established." [34].

\subsubsection{Renaissance of the "Grand Unified Theory?"}

In Section 1.3, some doubt was expressed as to whether a sequence comparison would confuse rather than confirm the evolution of biominerals from magnetite crystals of bacteria to hydroxyapatite in the human skeleton. A first draft of a unified theory of biomineralization, based mainly on morphogenesis, was published by Kirschvink and Hagedorn in "Biomineralization 2000" [4]. Although, initially this highly logical theory was accepted with great interest, major doubts were soon 
expressed when the Human Genome Project was completed by the Joint Genome Institutes, DOE, US Government. There followed by an extensive project of genome sequencing of 15 bacteria, including those of two magnetotactic species.

A surprising discovery was made in 2004 by Löwe [27], who reported that bacteria possess a cytoskeleton which consists of actin-like and tubulin-like proteins, with the bacteria showing low homologies in their DNA sequence to those of eukaryotic cells. Such experience suggests that genes and gene products, when combined with a knowledge of likely supposition of function, may (or will) allow the creation of a new unified theory. Today, however, more importance seems to be attached to the structure and function of proteins in biomineralization than to genes or to the derived amino acid sequences (see Sections 1.5.2.4 and 1.6).

\subsection{2}

\section{Filaments of Bacterial Acidic Polysaccharides as Matrices for Iron Oxide Crystals}

\subsubsection{Bacterial Iron Oxide Precipitations}

An extraordinary number of publications have described external iron oxide precipitates (for a review, see [35a,b]) compared to those relating to internal crystal formation (see Volume 1, Chapter 9). However, to date only one report exists describing polysaccharide filaments that are located outside, but still attached to, the bacterium, as templates for such minerals [36].

\subsubsection{Bacterial Core Strands of Acidic Exopolysaccharides Template Assembly of FeOOH Nanocrystal Fibers}

An organic polymer other than a polypeptide was identified by Banfield as a new templating element of bacterial biomineralization. In extended studies of iron oxyhydroxide-encrusted biofilms, and of minerals suspended in the surrounding groundwater, mineralized filaments were isolated and characterized using physical methods such as high-resolution transmission electron micrsocopy (HRTEM), energy-dispersive X-ray spectroscopy (EDX), scanning electron microscopy (SEM) and X-ray photo-emission electron microscopy (X-PEEM). The bacteria of the biofilm extruded polymer strands such that the precipitation reaction of the minerals was located on the outside. Each of these filaments contained a thin, pseudo-single crystal core (Fig. 1.3), surrounded by a porous layer of nanocrystal-
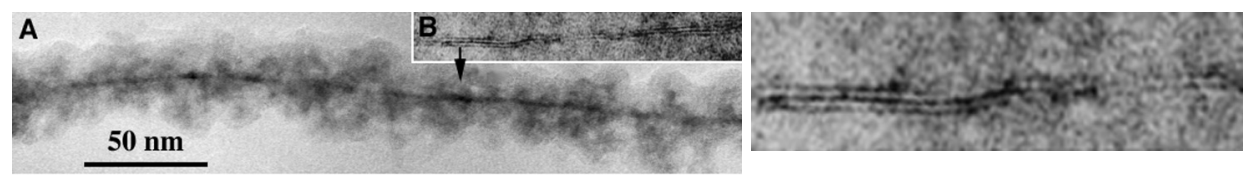

Fig. 1.3 FeOOH-mineralized filaments from the biofilm. A filament, which shows overall structure of thin alkageneite $(\beta$-FeOOH) core, surrounded by amorphous and crystallites of iron oxyhydroxide. Upper right: Alkageneite at the filament core. The $0.75-\mathrm{nm}$ lattice fringes are parallel to the filament length. (Modified from Ref. [36]; courtesy of J. Banfield.) 
line two-line ferrihydrite (Fig. 1.3d). These pseudo-single crystals, composed of akaganeite $(\beta$-FeOOH$)$, were located at the core and were 2 to $3 \mathrm{~nm}$ in diameter, thousands of nanometers in length, and formed a tunnel.

The organic polymer within this core of iron oxide filaments was also analyzed using physical methods such as X-PEEM combined with X-ray absorption nearedge structure spectroscopy (XANES). All of the data obtained indicated the presence of an acidic polysaccharide (most likely alginate). It was suggested that the polysaccharides might constitute a significant portion of the organics in each filament, and served as the mineral structure-directing components.

\subsubsection{Acidic Polysaccharides Mediating Formation of Complex Calcite $\left(\mathrm{CaCO}_{3}\right)$ Crystals in Pleurochrysis carterae, a Unicellular, Eukaryotic Organism}

The coccolithophore Pleurochrysis carterae, an alga of the marine plankton, was made prominent by the extensive studies conducted by Marsh (see Volume 1, Chapter 12), as was the similar coccolith, Emiliana huxleyi (see Volume 1, Chapter 13). In these organisms, 24 interlocking calcite crystals are assembled on the distal rim of an oval organic baseplate (see Volume 1, Fig. 12.2), and this construct is designated a coccolith. The initial crystallites are tethered on the coccolith ribbon, which consists most likely of polysaccharides. This ribbon is not a filament, but rather acts as a more two-dimensional band, and appears to be the site of calcite nucleation (see Volume 1, Fig. 12.4b, insert).

Three acidic polysaccharides, termed PS1, PS2, and PS3, were isolated and characterized, and their functions were analyzed by a series of immunolocalization studies and mutant analyses. PS1 and PS2 were found to be involved in ion accumulation, and PS3 in crystal growth and shaping. When examined in greater detail, the sulfated galacturonomannan PS3 (see Volume 1, Table 12.1) was found to be localized at the interface between the first crystallites and the membrane of the mineralizing vesicle, and to be responsible for acquiring anvil-like crystals by growth of the first crystallites. On completion of growth, all three polysaccharides were seen to be localized on the crystal coats and remained bound on the coccolith after extrusion to the surface of the cell.

\subsubsection{Polysaccharides or Peptides: Is There a "Unified Theory"?}

Although, at present, only single examples of polysaccharides have been recognized as being involved in biomineralization, recently developed glycomics research methods may now provide rapid of access to the analysis of these materials. Analytical electrophoretic separation techniques, including agarose-gel, high-performance capillary electrophoresis (HPCE) and fluorophore-assisted carbohydrate electrophoresis (FACE), have been introduced into the areas of structural analysis and quantification of complex polysaccharides, and notably of the acidic bacterial polysaccharides [37]. In this respect, considering that PS3 represents only $3 \%$ of the total acidic polysaccharides (PS1, 2 and 3), many new polysaccharides involved in the biomineralization remain to be discovered. Recently, the analytical possibilities in this area have been expanded by the introduction of 
mass spectrometry, while bioinformatics platforms have been developed to support the findings of glycomics and glycobiology research [38, 39].

In an important pioneering study, Arias showed that eggshell mineralization begins with the nucleation of calcite crystals on a discrete organic aggregation termed "mammillan", a proteoglycan which contains oversulfated keratin sulfate [40]. Of note, the polysaccharide region of mammillan was seen to resemble PS3 (see above), which is also a sulfated polysaccharide, but without a protein core.

\section{6}

Proteins of Similar Function and/or Structure, but Low Sequence Homology: Typical in Biomineralization

In Section 1.5.1, the suggestion was made that low homologies among the amino acid sequences of proteins involved in biomineralization might be common, an example being that of bacterial and eukaryotic actins, and therefore similarities in function and structure become crucial when identifying the corresponding genes. Some examples have been selected from elsewhere in Volume 1, and these appear to follow this distinctive feature.

\subsection{1}

\section{The Avian Eggshell Protein Ovocleidin-17, and Human Pancreatic Stone Protein}

The avian eggshell protein, ovocleidin-17 (OC17), occurs in the matrix of calcified layers of the eggshell (see Volume 1, Chapter 18), yet the "most similar" amino acid sequence found among the protein databases was for the human pancreatic stone protein (PSP). Although these two proteins have only $32 \%$ similarity of residues (see Volume 1, Sections 18.5.2 and 18.6), their 3-D structures are remarkably similar.

PSP, which is found in human pancreatic stones (as pathological calcite biominerals) was originally known as "lithostatine", because it was assumed by some to inhibit calcium carbonate precipitation in pancreatic fluid. Fetuin A has a similar role with regards to calcium phosphates in human extracellular fluids, including blood, lymph, and cerebrospinal fluid (see Volume 1, Chapter 24 and Volume 3, Chapter 22) [42]. Both, avian eggshell gland fluid and human pancreatic fluid are supersaturated with calcium carbonate, whereas human blood is rich in calcium phosphates and hydroxyapatite.

In chronic pancreatitis, PSP was shown to form large fibrils as a scaffold for stone formation, following the cleavage of an undecapaptide by activated trypsin. The proteins and proteoglucans [40] involved in the scaffold construction of the eggshell palisade and mammillary layers have been the subjects of intense investigation, with an initial proteomic analysis of the chicken eggshell having been reported in March 2006 [41] by Mann. 


\section{6 .2}

The Starmaker Protein of Zebrafish and Human Dentin Sialophosphoprotein (DSPP)

These two proteins exemplify the possibility of detecting genes (e.g., starmaker) by similarities in function, despite considerable differences in DNA sequences and even overall structure $[43,44]$.

Dentinogenesis imperfecta, which sometimes is also associated with hearing loss, manifests in humans in which the DSPP gene has undergone mutation. DSSP is not only responsible for the mineralization of human teeth by calcium phosphates (hydroxyapatite) (see Volume 3, Chapter 13), but is also expressed in the ears, where mineralization by calcium carbonate appears as the "ear stones" of octonia [44].

On the basis of extensive studies conducted by Nüsslein-Volhard [45], the zebrafish has today become a favored model organism for studying developmental and biological processes, and proved especially valuable in investigating the biomineralization of "ear stones" (which in the zebrafish are termed "otoliths"). Otoliths contain aragonite (a polymorph of calcium carbonate) and the Starmaker protein, and are excellent examples of natural composites (see Section 1.7).

\section{7}

\section{Composites: Inorganic-Organic Hybrid Materials}

Nature has invented amazingly very special materials that are known as "hybrids" or "composites", and which are assembled from at least an organic material and a mineral, often in complex morphologies. They are also often structured hierarchically, with the properties of the mineral undergoing change due to the presence and partition of the organic material.

Human inspiration and invention led to the development of a number of chemical approaches to these phenomena, and these are summarized in Volume 2, entitled Biomimetic and Bio-Inspired Chemistry. It was not until recently, however [44], that the first example of a bio-composite could be studied in otoliths, by using molecular biology methods, whereby the phased biosynthesis and phased decomposition of the successive shells - which consist of small crystallites of aragonite as well as mainly of the Starmaker protein - were analyzed.

The seeding particles, which form the core of the developing otoliths, consist of glycogen and bind to the extensions (the "kinocilia") of two special cells. These kinocilia correspond to filaments (as discussed above) as templates for the formation of otoliths. When mature, their core is surrounded by succeeding layers of an organic matrix, and layers of inorganic frames; the organic matrix represents a complete network of proteins, which is rich in acidic macromolecules, the Starmaker protein being the most abundant [46]. Crystallites of aragonite $\left(\mathrm{CaCO}_{3}\right)$ constitute the inorganic frames (for a review, see Volume 1, Chapter 17, especially Fig. 17.1). 
The Starmaker protein was the first to be shown capable of genetically controlling an inorganic process, namely crystal and shape formation. A reverse genetic approach was used for gene knock-down mediated by morpholino oligonucleotides (MO) [45] to special targets on the mRNA. The major advantage of this method was that, in subsequent experiments, the level of Starmaker protein could be regulated down in stepwise fashion. Thus, depending upon the MO concentration, a dramatic stepwise change was seen to occur in the otoliths, as: (i) they lost their ovoid form; (ii) they formed star-shaped otoliths together with another arrangement of the protein matrix; and (iii) the calcium carbonate polymorph aragonite was completely transformed into its polymorph, calcite.

Although otolith formation in the zebrafish (Danio rerio) is an exceptional example of biomineralization, the reason why this complex, inorganic-organic hybrid material is synthesized remains an open question. Likewise, its physical and chemical properties remain something of a mystery. However, it has been suggested that "... the mass load of the otoliths increased the sensitivity of the detection system ...", which referred to the sensory epithelium of the sensory hair cells and supporting cells [44, 47].

As described previously, it is possible to analyze otoliths by reducing their content of Starmaker protein within the layers of the organic matrix, and in this respect an excellent micromechanical method was developed [48] to measure the forces required to destroy silica shells (frustules) (see Volume 1, Chapter 5). However, were this method to be applied to the above-described otoliths, it would surely fail to provide the expected data, because the original otoliths would be changed to star-shaped and ultimately calcite-crystal-like otoliths; in other words, they adopt other geometric forms.

Due to its transparent and easily accessible embryos, D. rerio has recently become an important model organism in the study of skeletogenesis, both by developmental analysis and powerful genetic screening (for a review, see Volume 1, Chapter 20) [49].

Moreover, innovative studies (using atomic force microscopy and transmission electron microscopy) on the mechanical properties of wild-type and mutant zebrafish have been carried out in order to determine similarities between the zebrafish skeleton and human bone, at the nanomechanical level (see Volume 1, Chapter 22; Table 22.1). The most important and long-serving pioneer of biomineralization, S. Weiner, has described seven levels of hierarchical organization in the human long bones [50]. Nonetheless, although the zebrafish is only $4 \mathrm{~cm}$ in length, Cui and Wang observed a similar hierarchical structure of skeletal bone within this early vertebrate (see Volume 1, Chapter 22; Fig. 22.1).

Such high complexity and hierarchy - even of "lower" organisms - might discourage those of us intending to analyze these inorganic-organic hybrid materials in order to explain their mechanical properties by chemical and physicalchemical methods. The very basis of this approach relies on interactions between the surfaces of inorganic and organic matter, and the way in which a material is created with altered mechanical properties. 
In this respect, DiMasi succeeded in a surprising - but convincing - first step for the interaction between structured proteins, which had self-assembled into fiber network, and calcium carbonate in its early stages of biomimetic mineralization. Compared with its neighboring unstructured proteins, calcium carbonate stiffens the protein fibers selectively before crystal formation, and crystallizes only on such fibers (see Volume 2, Chapter 7). These results support the notion that proteins, when structured into filaments of fibers, are involved fundamentally in the precrystalline stages of biomineralization. These early-stage small quantities of calcium carbonate, by binding to filaments, generate an alteration in mechanical properties, namely an increased stiffness of their target, the filament.

These development point the way to broad developments in the basic reaction, in which the binding of inorganic ions causes a change in the mechanical properties of organic polymers. However, we are far from being able to reconstruct a skeleton based on this molecular interaction of the first reaction partners in a hierarchical process.

Consequently, in order to describe these highly complex constructs, such as a skeleton, mathematics suddenly became the center of attention, reviving the original ideas of D'Arcy Thompson.

\section{8}

\section{Finite Element Analysis and Conclusion}

The topic of biomineralization begins with a fundamental question regarding the interaction of inorganic and organic materials - an interaction which seems to have followed a clear direction since the origins of life. During the early stages of evolution, a specialized mode of biomaterial formation arose in bacteria utilizing ordered proteins and filaments for biosynthetic processes. Shortly afterwards (in evolutionary terms!), the development of biomaterials led to the creation of inorganic-organic hybrid materials which, until today, have eluded complete chemical and physical analyses aimed at determining their mechanical properties. In fact, most biominerals are characterized by a hierarchical order, which culminates in the skeletons of vertebrates.

In order to describe highly complex systems such as skeletons, Finite Element Analysis was introduced, and achieved great success (for a review, see Volume 3, Chapter 3). In this analysis, a skeleton would be covered by a mesh of points, termed "nodes", with the mesh having been programmed to include all material and structural data. Today, by using powerful computers it is possible to study the actions of varying forces (or loads) and, from a simplified point of view, Finite Element Analysis is able to answer the same questions as did the micromechanical method of Hamm (see Volume 1, Chapter 5), namely under what force an element would be destroyed. It is indeed amazing that the Finite Element Analysis of a skeleton is governed by only one physical quantity - the Force - together with 
the modulus of elasticity. Hence, the conclusion must be drawn that the major aim of biomineralization is STABILITY.

\section{References}

1 D'Arcy Thompson (Ed.), On Growth and Form. Cambridge University Press, Cambridge 1917.

2 (a) D'Arcy Thompson, On Growth and Form. Abridged edition, J.T. Bonner (Ed.), Cambridge University Press, Cambridge, 1961; (b) German edition (Transl. E.M. Fountain, M. Neff). Suhrkamp TB, Wissenschaft 410, 1983.

3 J.T. Bonner, The Cellular Slime Molds. Princeton University Press, 2nd edn., 1967.

4 J.L. Kirschvink, J.W. Hagadorn, in: E. Baeuerlein (Ed.), Biomineralization. From Biology to Biotechnology and Medical Application. Wiley-VCH, Weinheim, 2000, pp. 139-149.

5 H. Rauchfuß, Chemische Evolution und der Ursprung des Lebens. SpringerVerlag, Berlin, 2005 (in German only).

6 (a) S.W. Fox, K. Dose (Eds.), Molecular Evolution and the Origin of Life. Revised edition. Marcel Dekker, New York, 1977; (b) W.W. Leach, D.W. Nooner, J. Oro, Origin of Life 1978, 8, 113-122.

7 E. Baeuerlein, in: E. Baeuerlein (Ed.), Biomineralization. Progress in Biology, Molecular Biology and Application. Wiley-VCH, Weinheim, 2004, pp. 114.

8 (a) A.M. Belcher, in: E. Baeuerlein (Ed.), Biomineralization. From Biology to Biotechnology and Medical Application. Wiley-VCH, Weinheim, 2000, pp. 244-248; (b) S.R. Whaley, D.S. English, E.L. Hu, P.F. Barbara, A.M. Belcher, Nature 2000, 405, 665668.

9 New England Biolabs, Beverly, MA.

10 (a) R.R. Naik, L.L. Brott, S.J. Clarson, M.O. Stone, J. Nanosci. Nanotechnol. 2000, 2, 95-100; (b) R.R. Naik, S.J. Stringer, G. Agrarwal, S.E. Jones,
M.O. Stone, Nat. Mater. 2002, 1, 169172; (c) R.R. Naik, S.E. Jones, C.J. Murray, J.C. McAuliff, R.A. Vaia, M.O. Stone, Adv. Funct. Mater. 2004, 14, 25-30.

11 (a) J.N. Cha, K. Shimizu, Y. Zhou, S.C. Christiansen, B.F. Chmelka, T.J. Deming, G.D. Stucky, D.E. Morse, Proc. Natl. Acad. Sci. USA 1999, 96, 361-365; (b) Y. Zhou, K. Shimizu, I.N. Cha, G.D. Stucky, D.E. Morse, Angew. Chem. Int. Ed. 1999, 38, 779782.

12 D.A. Estell, C.J. Murray, P. Tijerina, Y. Chen, WO Patent 01/79479 A2, 2001.

13 (a) L.C. Gruen, Biochim. Biophys. Acta 1975, 386, 270; (b) M.J. Stillmann, C.F. Shaw, K.T. Suzuki (Eds.), Metallothioneins. VCH, New York, 1992; (c) D. Bar-Or, G. Curtis, N. Rao, N. Bampos, E. Lau, Eur. J. Biochem. 2001, 268, 42.

14 New England Peptide Inc.

15 T. Hyeon, Chem. Commun. 2003, 1, 927.

16 M.M. Tomczak, D.D. Glawe, L.F. Drummy, C.G. Lawrence, M.O. Stone, C.C. Perry, D.J. Pochan, T.J. Deming, R.R. Naik, J. Am. Chem. Soc. 2005, 127, 125577-125582.

17 J. Aizenberg, G. Lambert, S. Weiner, L. Addadi, J. Am. Chem. Soc. 2002, 124, 32-39.

18 K. Mann, B. Macek, J.V. Olsen, Proteomics 2006, 6, 3801-3810.

19 C. Jäger, T. Wenzel, W. Meyer-Zaika, M. Epple, Magn. Reson. Chem. 2006, 44, 573-580.

20 K. Zeth, S. Offermann, L.-O. Essen, D. Oesterhelt, Proc. Natl. Acad. Sci. USA 2004, 101, 13780-13785.

21 M.G. Wurster, J.S. Wettlaufer, J. Phys. Chem. B 1997, 101, 6132-6136.

22 H. Ishiguro, B. Rubinsky, Cryobiology 1994, 31, 483-500. 
23 S. Deville, E. Saiz, R.K. Nalla, A.P. Tomsia, Science 2006, 311, 515-518.

24 N. Poulsen, N. Kröger, J. Biol. Chem. 2004, 279, 42993-42999.

25 S. Vanis, O. Rheinbach, A. Klwonn, O. Prymak, M. Epple, Mat. Wiss. Werkstofftechn. (Engl.) 2006, 37, 469473.

26 E. Bäuerlein, Angew. Chem. Int. Ed. Engl. 2003, 42, 614-640.

27 (a) A. Löwe, F. van den Ent, L.A. Amos, Annu. Rev. Biophys. Biomol. Struct. 2004, 33, 177-198; (b) K.A. Michil, J. Löwe, Annu. Rev. Biochem. 2006, 75, 467-492.

28 S. Ullrich, M. Kube, S. Schübbe, R. Reinhardt, D. Schüler, J. Bacteriol. 2005, 187, 7176-7184.

29 U. Dobrindt, O. Hochhut, U. Hentschel, J. Hacker, Nat. Rev. Microbiol. 2004, 2, 414-424.

30 D. Schüler, Arch. Microbiol. 2004, 181, 1-7.

31 A. Komeili, Z. Li, D.K. Newman, G.J. Jensen, Science 2006, 311, 242-245.

32 A. Scheffel, M. Gruska, D. Faivre,

A. Linaroudis, J.M. Plitzko,

D. Schüler, Nature 2006, 440, 110114.

33 J. Pickett-Heaps, A.M.M. Schmid, L.A. Edgar, in: F.E. Round, D.J. Chapman (Eds.), Progress in Phycological Research, Volume 7. Biopress, Bristol, 1990, pp. 1-169.

34 G. Bugerolle, G. Bricheux, Protoplasma 1984, 123, 203-212.

35 (a) D. Fortin, S. Langley, Earth-Science Reviews 2005, 72, 1-19; (b) D. Fortin, T.J. Beveridge, in: E. Baeuerlein (Ed.), Biomineralization. From Biology to Biotechnology and Medical Application. Wiley-VCH, Weinheim, 2000, pp. 724.

36 C.S. Chan, G. De Stasio, S.A. Welch, M. Girasole, B.H. Frazer, M.V. Nesterova, S. Fakra, J.F. Banfield, Science 2004, 303, 1656-1658.

37 N. Volpi, E. Maccari, J. Chromatogr. B Analyt. Technol. Biomed. Life Sci. 2006, 834, 1-13.
38 T. Lütteke, A. Bohn-Lang, A. Loss, T. Goetz, M. Frank, C.W. von der Lieth, Glycobiology 2006, 16, 71R81R.

39 R. Raman, S. Raguram, G. Venkataraman, J.C. Paulson, R. Sasiekharan, Nat. Methods 2005, 2, 817-824.

40 J.L. Arias, A. Neira-Carillo, J.I. Arias, C. Escobar, M. Bodero, M. David, M.S. Fernandez, J. Mater. Chem. 2004, 14, 2154-2160.

41 W. Jahnen-Dechent, in: E. Baeuerlein (Ed.), Biomineralization. Progress in Biology, Molecular Biology and Application. 2nd edn. Wiley-VCH, Weinheim, 2004, pp. 245-267.

42 K. Mann, B. Macrk, J.V. Olsen, Proteomics 2006, 6, 3801-3810.

43 C. Söllner, M. Burghammer, E. BuschNentwich, J. Berger, H. Schwarz, C. Riekel, T. Nicolson, Science 2003, 302, 282-286.

44 C. Söllner, T. Nicolson, in: E. Baeuerlein (Ed.), Biomineralization. Progress in Biology, Molecular Biology and Application. 2nd edn. Wiley-VCH, Weinheim, 2004, pp. 229-242.

45 R. Dahm, R. Geisler, C. NüssleinVolhard, in: R.A. Meyers (Ed.), Encyclopedia of Molecular Cell Biology and Molecular Medicine. 2nd edn., Volume 15. Wiley-VCH, Weinheim, 2005, pp. 593-626.

46 G. Borelli, N. Mayer-Gostan, H. De Pontual, G. Boeuf, P. Payan, Calcif. Tissue Int. 2001, 69, 356-364.

47 A.J. Hudspeth, P.G. Gillespie, Neuron 1994, 12, 1-9.

48 C.E. Hamm, R. Merkel, O. Springer, P. Jurkoje, C. Maier, K. Prechtel, V. Smetacek, Nature 2003, 421, 841843.

49 S.J. Du, Y. Haga, in: E. Bauerlein (Ed.), Biomineralization. Progress in Biology, Molecular Biology and Application. 2nd edn. Wiley-VCH, Weinheim, 2004, pp. 283-304.

50 S. Weiner, H.D. Wagner, Annu. Rev. Mater. Sci. 1998, 28, 271-298. 